\title{
The partial reinforcement effect as a function of surgical anosmia
}

\author{
STEPHEN F. DAVIS, MARY NELL MOLLENHOUR, and LARRY FLOOD \\ Austin Peay State University, Clarksville, Tennessee 37040 \\ JOHN D. SEAGO \\ Concord College, Athens, West Virginia 24712 \\ and \\ ROBERT E. PRYTULA \\ Middle Tennessee State University, Murfreesboro, Tennessee 97192
}

\begin{abstract}
Two groups of surgically anosmic rats received continuous or partial reinforcement, respectively, during the first phase (60 trials) of a two-phase experiment. During the second phase, all subjects received 40 extinction trials. No significant differences between the continuous and partial reinforcement groups were found during Phase I. However, significant PREs were shown during extinction in start, run, and goal measures.
\end{abstract}

A recent series of studies (Davis, Harper, \& Seago, 1975: Davis \& Seago, 1975; Marrero, Davis, \& Seago, 1973) have concerned themselves with investigating the effects of surgical anosmia on behavior in the straight runway. The results of these studies have suggested that one effect of rendering the rat subject surgically anosmic is to reduce incentive motivation. For example, performance differences between anosmic subjects receiving large and small reward magnitudes, respectively, failed to develop in both the Davis et al. (1975) and Marrero et al. (1973) studies, while significant magnitude effects were shown by both normal and sham-operated subjects. Moreover, the results of the Davis et al. (1975) study indicated that the performance of anosmic subjects abruptly shifted from large to small reward declined gradually. This may be contrasted with the precipitous decrements displayed by normal and sham subjects in the Davis et al. (1975) study and in other successive reward-shift studies (e.g., Crespi, 1942; Zeaman, 1949). On the other hand, the Davis and Seago (1975) report indicated that negative contrast effects typically found in differential conditioning studies (e.g., Ludvigson \& Gay, 1967) employing normal subjects were not shown by anosmic subjects.

The logical extension of this series of research projects would appear to be an investigation into the effects of anosmia on performance in the partial reinforcement situation. Increased resistance to extinction following partial reinforcement training is ont of the most durable phenomena to be encountered in the literature.

This research was supported by a Tower Fund Research Grant from Austin Peay State University to the first author and a Faculty Research Grant from Middle Tennessee State University to the last author.
However, it would seem tenable that even this venerable effect might be subject to some type of modfication by the apparently lowered motivational state of the anosmic subjects.

\section{METHOD}

\section{Subjects}

Sixteen male albino rats purchased from the Sprague-Dawley Co., Madison, Wisconsin, served as subjects. All subjects were rendered anosmic via the aspiration technique (see Davis \& Seago, 1975 for a more complete description of the surgical procedures employed). All subjects were approximately 100 days old at the inception of the study, and were housed in individual cages with water continuously available. Following recovery from surgery ( 2 weeks prior to the start of pretraining) all subjects were placed on a food-deprivation schedule which maintained them at $85 \%$ ad lib body weight for the duration of the experiment. Maintenance of the deprivation schedule took place following the daily experimental session.

\section{Apparatus}

A straight runway (more fully described in Davis et al., 1975) having a $38.10-\mathrm{cm}$ startbox, $91.44-\mathrm{cm}$ black run section, and $30.48-\mathrm{cm}$ black goal section, served as the experimental apparatus. A microswitch, mounted on the startdoor, in conjunction with a series of photoelectric cells, successively activated and stopped a series of three Standard electric timers, thus yielding start, run, and goal latencies for each trial.

\section{Procedure}

At the beginning of deprivation, the subects were randomly divided into two equal groups: PR (partial reinforcement) and CR (continuous reinforcement). A 5 -day pretraining phase immediately preceded the start of the experiment proper. During pretraining, all subjects were: (1) handled and tamed-Days 1-2, (2) allowed to exp'ore the unbaited apparatus-Days 3-5, and (3) habituated to the reward pellets in the home cage-Days 1-5. Acquisition (60 trials, 4 trials per day) followed pretraining. 


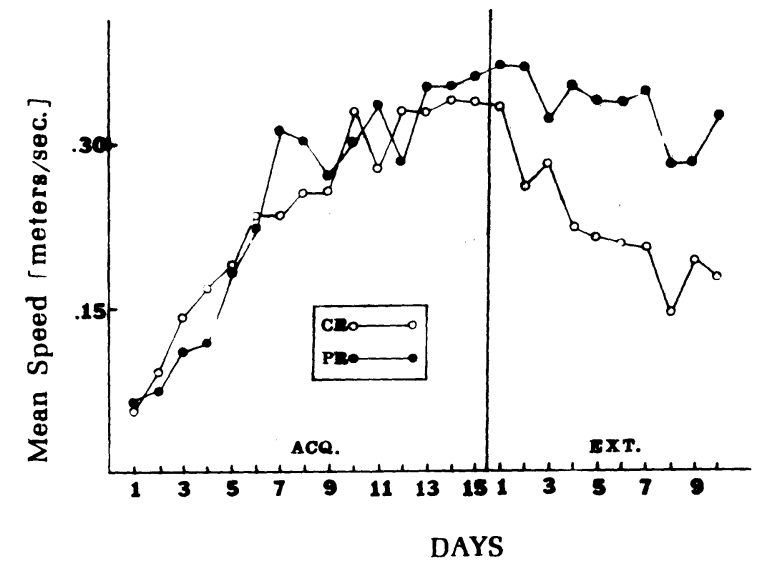

Figure 1. Mean start eppeeds (meters per second) for Groups CR and PR during acquisition and extinction.

During acquisition, subjects in Group CR were rewarded (10 45-mg pellets) on each trial, while subjects in Group PR received reward (10 45-mg pellets) on only two of the four daily trials. The determination of the rewarded trials for subjects in Group PR was done randomly with the restriction that no fourtrial sequence of reward(R)-nonreward(N) trials could be experienced by a subject more than twice in succession. A 40-trial (4 trials per day) extinction phase was administered to all subjects immediately following acquisition. Subjects were removed from the goalbox immediately upon consuming the pellets on $\mathbf{R}$ trials or following a $30-\mathrm{sec}$ confinement period on $\mathrm{N}$ trials.

\section{RESULTS AND DISCUSSION}

Start, run, and goal latencies when reciprocated and multiplied by the appropriate constant yielded speed scores in terms of meters per second. A repeated measures analysis of variance was performed on the speed data for each phase of the experiment. As both the graphical representations and results of statistical analyses were highly similar for all three measures, only the start speeds will be presented (see Figure 1). The results of the acquisition analyses indicated that the Days factor was significant, $F(14,196)=38.53, p<.01$. The extinction analyses yielded significance for the Groups factor, $F(1,14)=4.79, \mathrm{p}<.05$, the Days factor, $F(9,126)=2.64, p<.01$, and the Groups by Days interaction, $F(9,126)=8.96, p<.01$. The significant Groups by Days interaction was further probed through the use of simple main effects analyses. The results of these analyses indicated that Groups CR and PR did not differ significantly on Days 1 and 3 of extinction. However, Group PR ran significantly $(p<.01)$ faster than did Group CR on all remaining days during the extinction phase.
As can be seen from Figure 1, the most striking feature of the present data was the development of a pronounced partial reinforcement effect during extinction. If one would be content to view the results of this study in isolation, then a relatively straightforward conclusion could be arrived at, namely, that surgical anosmia did not appear to have any effect on behavior in the runway situation (i.e., the results of the present study are compatible with those obtained in similar studies using intact animals).

However, if these results are cast into the context of the previous anosmia studies that have been conducted in this laboratory, then a somewhat different picture tends to emerge. As already mentioned, the previous studies have shown, rather persuasively, that one effect of rendering the rat subject anosmic is to reduce incentive motivation. The development of the partial reinforcement effect during the extinction phase of the present study would suggest that this phenomenon may not be based upon an incentive motivation or frustration model, at least where the anosmic subject is concerned. Rather, it would appear that a discrimination interpretation might best account for the present results. Judging from the present data, it could be argued that the subjects in Group PR simply found it more difficult to discriminate between acquisition and extinction than did the subjects in Group CR.

\section{REFERENCES}

CrespI, L. P. Quantitative variation of incentive and performance in the white rat. American Jourmal of Psychology, 1942, 55, 467-517.

Davis, S. F., Harper, W. E., \& Seago, J. D. Runway performance of normal, sham, and anosmic rats as a function of magnitude of reward and magnitude shift. Bulletin of the Psychonomic Society, 1975, 6, 367-369.

Davis, S. F.. \& SEAGo, J. D. Differential conditioning as a function of surgical anosmia. Bulletin of the Psychonomic Society, 1975, 6. 10-12.

Ludvigson, H. W., \& GAY, R. A. An investigation of conditions determining contrast effects in differential reward conditioning. Journal of Experimental Psychology, 1967. 75. 37-42.

Marrero, B., Davis, S. F., \& Seago, J. D. Runway performance of normal and anosmic rats as a function of reward magnitude: A preliminary report. Bulletin of the Psychonomic Society, 1973, 2, 375-376.

ZEAMAN, D. Response latency as a function of amount of reinforcement. Journal of Experimental Psychology, 1949, 39. 466-483.

(Received for publication January 16, 1976.) 